\title{
Effects of resin-based temporary filling materials against dentin demineralization
}

\author{
Toru SHIIYA ${ }^{1,4,5}$, Kiyoshi TOMIYAMA 1,4,5, Junko IIZUKA'1,4,5, Haruhiko HASEGAWA ${ }^{1,4,5}$, Erika KURAMOCHI ${ }^{1,4,5}$, \\ Fukue FUJINO2 ${ }^{2}$, Katsura OHASHI ${ }^{3,4,5}$, Tomotaro $\mathrm{NIHEI}^{3,4,5}$, Toshio TERANAKA ${ }^{1}$ and Yoshiharu MUKAII ${ }^{1,4,5}$
}

\author{
${ }^{1}$ Department of Cariology and Restorative Dentistry, Graduate School of Dentistry, Kanagawa Dental University, 82 Inaoka-cho, Yokosuka, Kanagawa \\ 238-8580, Japan \\ ${ }^{2}$ Department of Dental Hygiene, Junior College, Kanagawa Dental University, 82 Inaoka-cho, Yokosuka, Kanagawa 238-8580, Japan \\ ${ }^{3}$ Department of Clinical Biomaterials, Graduate School of Dentistry, Kanagawa Dental University, 82 Inaoka-cho, Yokosuka, Kanagawa 238-8580, \\ Japan \\ ${ }^{4}$ Institute of Oral Regenerative Medicine, Kanagawa Dental University, 82 Inaoka-cho, Yokosuka, Kanagawa 238-8580, Japan \\ ${ }^{5}$ Institute for Research of Disaster Dental Medicine in Yokosuka and Shonan, Kanagawa Dental University, 82 Inaoka-cho, Yokosuka, Kanagawa \\ 238-8580, Japan \\ Corresponding author, Yoshiharu MUKAl; E-mail: mukai@kdu.ac.jp
}

\begin{abstract}
This study investigated the in vitro anti-demineralization effects of resin-based temporary filling materials containing surface prereacted glass-ionomer (S-PRG) filler on dentin. Bovine root dentin specimens with a $3 \times 3 \mathrm{~mm}$ experimental surface were divided into four treatment groups: DuraSeal (DU) as a control, S-PRG filler-free temporary material (S0), material containing 10\% (S10) and $20 \%$ (S20) S-PRG filler. Each material was applied to $3 \times 2 \mathrm{~mm}$ of the experimental surface, and the specimens were immersed in $8 \%$ methylcellulose gel demineralization system for one week at $37^{\circ} \mathrm{C}$. Mineral profiles and integrated mineral loss (IML) of lesions induced on the surface $(3 \times 1 \mathrm{~mm})$ adjacent to the materials were computed by transversal microradiography. S10 and S20 yielded thick surface layers and shallow lesion bodies, with significantly lower IML than DU and S0 ( $p<0.05$, Tukey's test). These findings indicate that temporary filling resin-based materials containing over $10 \%$ of S-PRG filler content have anti-demineralization effects on adjacent dentin.
\end{abstract}

Keywords: S-PRG filler, Resin-based temporary filling material, Anti-demineralization, Dentin, Transversal microradiography

\section{INTRODUCTION}

Temporary resin-based filling materials are frequently used to fill prepared cavities during indirect restorations ${ }^{1-6)}$. These materials are easy to use, both in filling cavities and in removing before final restorations. Studies have suggested, however, that these materials lack sealing ability ${ }^{3)}$ and that bacterial contamination can occur in the cavities ${ }^{3,7}$.

Surface pre-reacted glass-ionomer (S-PRG) filler release various ions, including fluoride, strontium, sodium, boron, aluminum and silicate ions ${ }^{8}$. In particular, fluoride and strontium ions released by S-PRG filler may alter hydroxyapatite in dentin to fluoridated apatite, fluorapatite or strontium apatite during the course of demineralization and remineralization ${ }^{9}$. In addition, this filler may play important roles in mineral induction ${ }^{10)}$. S-PRG filler consist of three layers: an outer surface-modifying layer that reinforces the glass-ionomer layer, a middle layer glass-ionomer layer that forms the glass surface, and an inner core consisting of multifunctional glass ${ }^{11)}$. Tooth coating material containing this filler was reported to have anti-demineralization activities against bovine enamel $^{12)}$ and dentin ${ }^{13)}$. Moreover, the composite resin containing this filler may reduce dental bacterial adherence and plaque formation ${ }^{14)}$.

Temporary filling material with S-PRG filler has shown better marginal sealing ability, with a lower coefficient of thermal expansion, than other temporary materials on the market ${ }^{15)}$. The powder of this material contains polymethyl methacrylate (PMMA), $10 \%$ S-PRG filler and initiator, and the liquid contains benzyl benzoate, methyl methacrylate (MMA) and initiator. To date, however, the anti-demineralization effects of S-PRG filler containing resin-based temporary filling material have not been investigated. This study was therefore designed to investigate the anti-demineralization effects of the temporary filling materials on dentin in vitro. The null hypothesis was that the S-PRG filler containing temporary filling material did not have antidemineralization effects on adjacent dentin.

\section{MATERIALS AND METHODS}

\section{Preparation of dentin specimens}

The experimental procedures are outlined in Fig. 1. The preparation procedure was performed by reference to previous reports ${ }^{9,13)}$. Cylindrical dentin roots were obtained from the lower central incisors of 2- to 3-yrold cattle using a sectioning machine (Isomet Low Speed Saw, Buehler, Lake Bluff, IL, USA). Each cylinder was cut into halves longitudinally with a diamondcoated-wire sectioning machine (Well type 3242, Walter Ebner, Mannheim, Germany). Experimental surfaces, approximately $5 \times 4 \mathrm{~mm}$ in size, were prepared by cutting $1 \mathrm{~mm}$ each from the buccal and lingual root surfaces with the wire sectioning machine and polished with 2000grit waterproof abrasive paper (FUJI STAR, Sankyo Rikagaku, Saitama, Japan) to obtain flat surfaces. 
The specimens were cleaned ultrasonically for $5 \mathrm{~min}$ with deionized water, and a $3 \times 3 \mathrm{~mm}$ window on each specimen was made with sticky wax (New Sticky Wax,

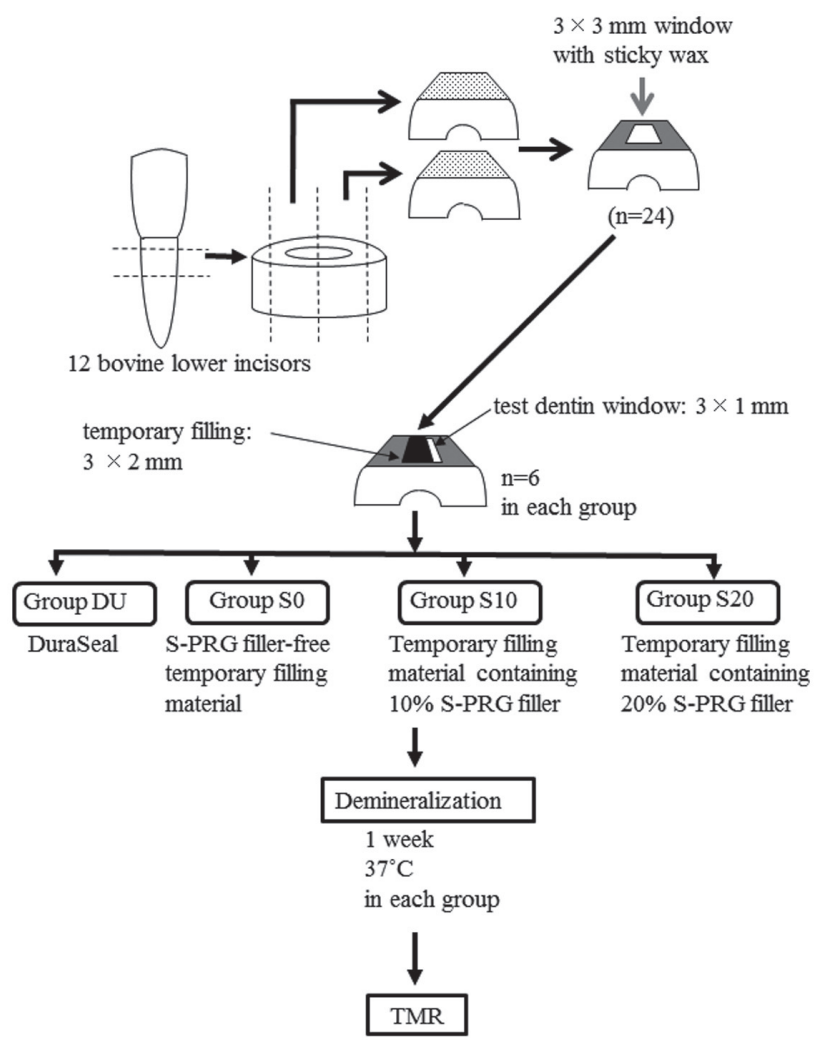

Fig. 1 Outline of experimental procedures.
GC, Tokyo, Japan).

Treatment of dentin experimental surfaces

Twenty-four dentin specimens were randomly divided into four groups of six each. Each group was treated with one of four different temporary filling materials (Table 1): DuraSeal (DU; Reliance Dental, Alsip, IL, USA; as control), S-PRG filler-free temporary filling material (S0; Shofu, Kyoto, Japan), temporary filling material containing 10\% S-PRG filler (S10; PRG PROTECT SEAL, Shofu) and temporary filling material containing $20 \%$ S-PRG filler (S20; Shofu). Liquid and powder of each resin-based material were mixed with a small thin brush, and each was applied to a $3 \times 2 \mathrm{~mm}$ area of each dentin sample as a thickness of approximately $500 \mu \mathrm{m}$ $(450-550 \mu \mathrm{m})$. Samples which had the materials with thickness under $450 \mu \mathrm{m}$ or over $550 \mu \mathrm{m}$ were excluded. All treatment procedures were performed by the same individual.

\section{Demineralization}

For each of the four experimental groups, we placed six specimens at the bottom of a plastic container (BOTTLE PP (120 mL), AS ONE, Osaka, Japan) and poured $40 \mathrm{~mL}$ of $8 \%$ methylcellulose gel (Methocel MC, Fluka, Buchs, Switzerland). After $24 \mathrm{~h}, 70 \mathrm{~mL}$ of acid buffer $(50 \mathrm{mM}$ acetic acid, $1.5 \mathrm{mM} \mathrm{CaCl}_{2}, 0.9 \mathrm{mM} \mathrm{KH}_{2} \mathrm{PO}_{4}, \mathrm{pH}$ 5.0) were poured to each container. All containers were kept for one week at $37^{\circ} \mathrm{C}^{13)}$.

\section{Transversal microradiography (TMR)}

Three $300 \mu \mathrm{m}$ thick sections were cut perpendicularly to the experimental surface using the diamond-coated-wire sectioning machine from each specimen. The sections

Table 1 Materials used

\begin{tabular}{|c|c|c|c|c|}
\hline Group & Material & Ingredients & Lot number & Manufacturer \\
\hline DU & DuraSeal $^{\mathrm{a}}$ & $\begin{array}{c}\text { Powder: PMMA, BPO } \\
\text { Liquid: MMA, DBP, DMPT }\end{array}$ & $\begin{array}{l}121411 \text { (Powder) } \\
120911 \text { (Liquid) }\end{array}$ & Reliance Dental \\
\hline S0 & $\begin{array}{l}\text { S-PRG filler-free } \\
\text { temporary filling } \\
\text { material }\end{array}$ & $\begin{array}{l}\text { Powder: PMMA, Initiator, Others } \\
\text { Liquid: Benzyl benzoate, MMA, } \\
\text { Initiator, Others }\end{array}$ & $\begin{array}{l}120420 \text { (Powder) } \\
111013 \text { (Liquid) }\end{array}$ & Shofu \\
\hline $\mathrm{S} 10$ & $\begin{array}{l}\text { Temporary filling } \\
\text { material containing } \\
10 \% \text { S-PRG filler }\end{array}$ & $\begin{array}{c}\text { Powder: PMMA, S-PRG filler } \\
\text { (mean dia. } 3.0 \mu \mathrm{m} \text {, Filler contents: } 10 \mathrm{wt} \% \text { ), } \\
\text { Initiator, Others } \\
\text { Liquid: Benzyl benzoate, MMA, } \\
\text { Initiator, Others }\end{array}$ & $\begin{array}{l}120420 \text { (Powder) } \\
111013 \text { (Liquid) }\end{array}$ & Shofu \\
\hline $\mathrm{S} 20$ & $\begin{array}{l}\text { Temporary filling } \\
\text { material containing } \\
20 \% \text { S-PRG filler }\end{array}$ & $\begin{array}{c}\text { Powder: PMMA, S-PRG filler } \\
\text { (mean dia. } 3.0 \mu \mathrm{m} \text {, Filler contents: } 20 \mathrm{wt} \% \text { ), } \\
\text { Initiator, Others } \\
\text { Liquid: Benzyl benzoate, MMA, } \\
\text { Initiator, Others }\end{array}$ & $\begin{array}{l}120420 \text { (Powder) } \\
111013 \text { (Liquid) }\end{array}$ & Shofu \\
\hline
\end{tabular}

PMMA: polymethyl methacrylate; BPO: benzoyl peroxide; MMA: methyl methacrylate; DBP: di- $n$-butyl phthalate; DMPT: $N$, $N$-dimethyl-p-toluidine; S-PRG filler: Surface pre-reacted glass-ionomer filler.

a The ingredients of DuraSeal were referred to Kawahara et al. ${ }^{5}$, and Tanaka et al. ${ }^{6}$. 
were placed on a perspex holder in a droplet of water and covered with thin polyester sheets to avoid dentin shrinkage ${ }^{16)}$. Together with an aluminum step wedge of 13 steps, ranging from 0 to $300 \mu \mathrm{m}$ in thickness, the sections were radiographed on a high-resolution glass film plate (High-Resolution Plate, Konica Minolta, Tokyo, Japan) with a nickel-filtered $\mathrm{Cu}-\mathrm{K} \alpha$ source operated at $15 \mathrm{~mA}$ and $25 \mathrm{kV}$ for $20 \mathrm{~min}$ (PW3830, Spectris, Surrey, UK).

The radiographic images were analyzed using a microscope/video camera/microcomputer setup and software (TMR2000, Inspektor Research System, Amsterdam, The Netherlands) ${ }^{17}$. The $300 \mu \mathrm{m}$ area adjacent to the material was analyzed. The output parameters obtained were the mineral content $v s$. depth profiles of the lesions, lesion depth (LD), and integrated mineral loss (IML) ${ }^{18,19)}$.

\section{Fluoride release}

Metal molds (15 mm inner diameter, $1 \mathrm{~mm}$ thickness, $n=6$ /group) were filled with $\mathrm{S} 10$ and $\mathrm{S} 20$, at a powder/ liquid ratio of $2 \mathrm{~g} / \mathrm{mL}$, covered with celluloid strips on the top and bottom, and pressed by hand. The disks were polished lightly with 2000-grit waterproof abrasive paper to remove the resin-rich superficial layer. Each disk was immersed in $5 \mathrm{~mL}$ deionized water for one week at $37^{\circ} \mathrm{C}$. A $0.3 \mathrm{~mL}$ of total ionic strength adjustment buffer (TISAB III, Thermo Electron, Beverly, MA, USA) was added to $3 \mathrm{~mL}$ of each eluate. Fluoride concentrations were measured with a combination fluoride electrode (Orion 9609BNWP ionplus Sure-Flow Fluoride, Thermo Fisher Scientific, Waltham, MA, USA) connected to a fluoride-ion meter (720Aplus, Thermo Fisher Scientific). The amount of fluoride released per unit surface area $\left(\mathrm{cm}^{2}\right)$ of the disk was computed.

\section{Statistical analysis}

IML and LD in the four groups were compared by oneway ANOVA, followed by Tukey's post hoc comparison test, and fluoride concentrations in two groups were compared by $t$-tests. All statistical analyses were performed using a statistical software package (SPSSPC software version 10.1, SPSS Japan, Tokyo, Japan), with $p<0.05$ defined as statistically significant.

\section{RESULTS}

\section{Representative TMR images and profiles}

Figure 2 shows TMR images (a) and mineral profiles (b) of representative specimens in each experimental group. The TMR images of DU and S0 were very similar and showed an unclear marginal surface layer and a severely demineralized subsurface lesion. In contrast, the TMR images of S10 and S20 were similar and showed distinct surface layers, with greater radio-opacity of the lesion body than observed with DU and S0.

Mineral profiles of DU and S0 showed extremely low and indistinct peaks near the surface and heavy lesion bodies. However, the profiles of S10 and S20 showed welldefined peaks with a high volume percent of minerals in (a)

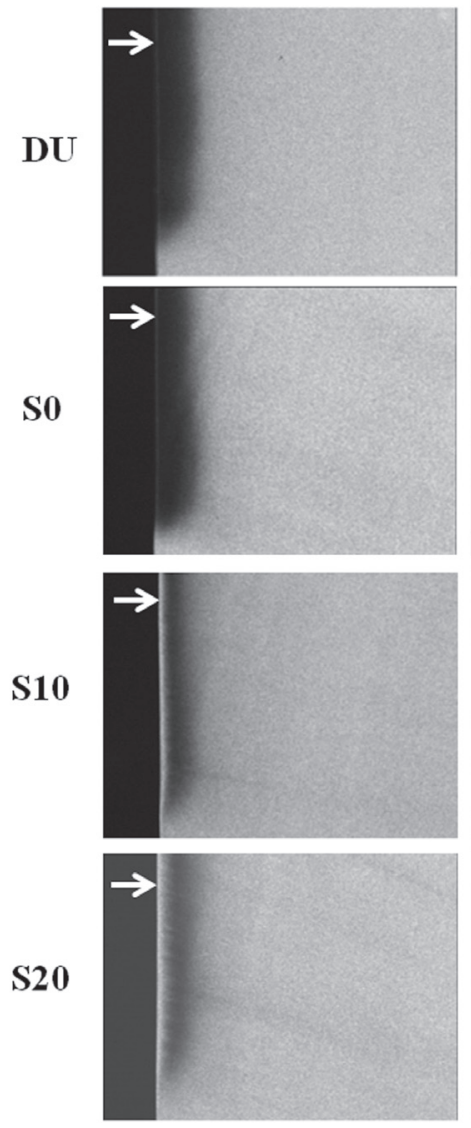

Fig. 2 Representative TMR images (a) and mineral profiles (b).

The arrow indicates the dentin surface. (a) The TMR images of S10 and S20 were similar and showed clear surfaces (arrows), with the radio-opacity of the lesion bodies significantly greater than those of DU and S0. (b) In the microradiograms, LD was determined as the distance from the surface to the position at which the mineral content is $95 \%$ of that of the sound dentin, and IML was defined as the integrated difference between the microradiogram of the sample and that of the sound sample (grey area). the near-surface region at depths of 5-10 $\mu \mathrm{m}$ and slight lesion bodies in deeper areas.

\section{Average mineral profiles}

The averaged mineral profiles of the four groups are shown in Fig. 3. The surface mineral peaks of DU and S0 were quite low, whereas those of S10 and S20 were almost 30-40 vol\%. In addition, severely demineralized lesion bodies were observed in DU and S0, whereas mineral volumes in S10 and S20 were higher than those of DU and S0. 


\section{$I M L$ and $L D$}

Table 2 shows intergroup comparisons of mean IML $(\operatorname{vol} \% \times \mu \mathrm{m})$ and $\mathrm{LD}(\mu \mathrm{m})$ of the six sections in the four experimental groups. IML of S10 $(2,979 \pm 241)$ and S20 $(2,814 \pm 569)$ were significantly lower than those of DU $(5,223 \pm 341)$ and S0 $(5,004 \pm 404)(p<0.05)$, but there was no significant difference between S10 and S20 ( $p>0.05)$.

LD of DU (291 \pm 28$)$ was similar to that of S0 $(272 \pm 56)$ $(p>0.05)$, but statistically higher than those of $\mathrm{S} 10$ $(203 \pm 29)$ and S20 $(213 \pm 46)(p<0.05)$.

\section{Fluoride release}

Experimental disks from specimens containing $10 \mathrm{wt} \%$ and $20 \mathrm{wt} \%$ of S-PRG filler released $0.55 \pm 0.09$ and $0.80 \pm 0.16 \mu \mathrm{g} / \mathrm{cm}^{2}$ fluoride ions, respectively, into deionized water. The difference between these two groups was statistically significant $(p<0.05)$.

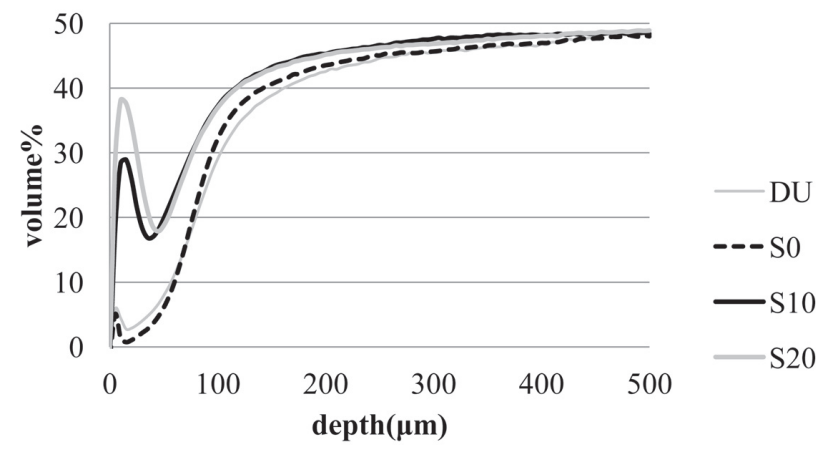

Fig. 3 Average mineral profiles formed in the four groups $(n=6)$.

The surface mineral peaks of DU and S0 were extremely low, whereas those of S10 and S20 were almost 30-40 vol\%. Severely demineralized lesion bodies were observed in the DU and S0 groups, on the other hand, mineral loss in deeper regions was less in the S10 and S20 groups. S10 and S20 had thick surface layers and slight lesion bodies.

\section{DISCUSSION}

The findings of this study rejected our null hypothesis. Briefly, the profiles of S10 and S20 consisted of welldefined peaks with a high volume percent of minerals in the near-surface region and slight lesion bodies in deeper areas. IML of S10 and S20 were significantly lower than those of DU and S0 $(p<0.05)$, but there was no significant difference between S10 and S20 ( $p>0.05)$.

Between the time a tooth is prepared and the final restoration is completed, it is important that the patient be comfortable and that the tooth be protected and stabilized with an adequate temporary restoration ${ }^{20)}$. Many types of temporary restorations, such as hydraulic-setting cements, zinc oxide-eugenol cement and resin temporary restoration, have been used, and in particular, resin-based temporary materials has become popular. Because dentists could remove them easily with explorer, when they started to try-in of the casting on the tooth. However, they could not accomplish good marginal sealing ability, though it was very important to protect prepared cavity walls from bacterial contamination ${ }^{3)}$. Recently developed resin-based temporary material containing S-PRG filler had better marginal sealing ability, with lower expansion in response to thermal stress, than conventional resin-based materials ${ }^{15)}$.

As the resin-based temporary filling material, DuraSeal has spread at many dental general practitioners. Di- $n$-butyl phthalate (DBP) included in DuraSeal liquid was one of the most commonly used plasticizers ${ }^{5,6)}$, which were considered relatively nontoxic $^{21)}$. On the other hand, there was a report that the highest incidence of malformed fetuses occurred after administration with DBP on 13-15 days in rats ${ }^{22)}$. S0, S10 and S20 contained benzyl benzoate instead of DBP. This would be why the manufacturer took the health considerations.

The temporary filling materials containing $10 \%$ or $20 \%$ S-PRG filler showed statistically less mineral loss at the adjacent dentin against demineralization than DuraSeal and filling material without S-PRG filler. Microradiographic analyses of the S10 and S20 groups showed increased mineral volume percent at the

Table 2 Intergroup comparisons of integrated mineral loss (IML) and lesion depth (LD)

\begin{tabular}{ccc}
\hline Groups & IML $(\operatorname{vol} \% \times \mu \mathrm{m})$ & $\mathrm{LD}(\mu \mathrm{m})$ \\
\hline DU & $5,223(341)^{\mathrm{a}}$ & $291(28)^{\mathrm{a}}$ \\
S0 & $5,004(404)^{\mathrm{a}}$ & $272(56)^{\mathrm{a}, \mathrm{b}}$ \\
S10 & $2,979(241)^{\mathrm{b}}$ & $203(29)^{\mathrm{c}}$ \\
S20 & $2,814(569)^{\mathrm{b}}$ & $213(46)^{\mathrm{b}, \mathrm{c}}$ \\
\hline
\end{tabular}

Mean $( \pm \mathrm{SD}), n=6$

Values with the same superscript letters did not show significant differences between groups.

IML of S10 and S20 were significantly lower than those of DU and S0 $(p<0.05)$, but there was no significant difference between $\mathrm{S} 10$ and $\mathrm{S} 20(p>0.05)$.

DU: DuraSeal; S0: S-PRG filler-free; S10: 10\% S-PRG filler; S20: 20\% S-PRG filler. 
surface and overall IML was reduced compared with S0, but these effects were not dose-dependent. Fluoride released by the S-PRG filler likely induces fluoroapatitelike precipitations in lesion bodies, inhibiting further demineralization ${ }^{23}$. In contrast to our finding, showing that IML was similar for S10 and S20, a study investigating the amount of fluoride ions released into deionized water over one week by experimental denture base resins containing 10 and $20 \mathrm{wt} \%$ S-PRG filler found that the $20 \mathrm{wt} \%$ resin released significantly more fluoride ions than the $10 \mathrm{wt} \% \mathrm{resin}^{24)}$. Also in this study, it was sure that temporary filling material containing 20\% S-PRG filler released significantly more fluoride ions than that containing $10 \%$ S-PRG filler. However, in this investigation, demineralization was performed eight times of medium as fluoride releasing study. We assumed that fluoride ion released from the both materials in the demineralization medium would be much weaken to the level of same IML achieved. On the other hand, it will be necessary to confirm the anti-demineralization effect of these materials and determine filler volume requirement under the narrow space model simulating leakage.

Although IML differed significantly between S-PRG containing and non-containing materials, LD did not. LD, however, may be controlled by the $\mathrm{pH}$ of the solution rather than by the fluoride ion concentration ${ }^{25)}$, suggesting that LD may not be an accurate parameter for measuring demineralization.

Fluoride and strontium ions are released from S-PRG filler containing temporary filling materials and react with hydroxyapatite to form fluoroapatite, strontium apatite and/or fluoridated apatite ${ }^{9)}$. Fluoride in saliva has been reported to provide more protection against demineralization than enamel-bound fluoride. Even at low $\mathrm{pH}$, fluoride ion in saliva would increase the saturation degree of fluoroapatite, contributing to the remineralization of teeth ${ }^{26,27)}$. Strontium ion was also involved in the remineralization process of caries dentin $^{28)}$, and the remineralization effect was affected by concentration of fluoride ions when used in conjunction with them ${ }^{29}$. Moreover, silica and hydroxyapatite nanoparticles have been reported to infiltrate into demineralized dentin, acting as seeds within the collagen matrix ${ }^{30)}$. Therefore, we considered that the materials had anti-demineralization effects. Further investigations for clinical use of these materials are required.

\section{CONCLUSION}

The null hypothesis of this study was rejected for IML, indicating that the resin-based temporary filling materials containing $10 \%$ or $20 \%$ S-PRG filler achieved anti-demineralization effects on adjacent dentin.

\section{ACKNOWLEGMENTS}

This work was supported, in part, by a Grant-in-Aid for Scientific Research (C) from the Japan Society for the Promotion of Science (JSPS No. 24592888) and MEXT-Supported Program for the Strategic Research
Foundation at Private Universities, S1203004, 20122014. This research is free of conflict of interest.

\section{REFERENCES}

1) Abadie FR. Plastic stopping —update. J Prosthet Dent 1979; 42: 470-476.

2) Terata R, Yoshinaka S, Nakashima K, Kubota M. Effect of resinous temporary material on tensile bond strength of resin luting cement to tooth substrate. Dent Mater J 1996; 15: 4550 .

3) Hotta M, Nakajima H, Yamamoto K, Aono M. Antibacterial temporary filling materials: the effect of adding various ratios of Ag-Zn-Zeolite. J Oral Rehabil 1998; 25: 485-489.

4) Terata R, Nakashima K, Kubota M. Effect of temporary materials on bond strength of resin-modified glass-ionomer luting cements to teeth. Am J Dent 2000; 13: 209-211.

5) Kawahara T, Nomura Y, Tanaka N, Teshima W, Okazaki M, Shintani H. Leachability of plasticizer and residual monomer from commercial temporary restorative resins. J Dent 2004; 32: $277-283$.

6) Tanaka N, Nomura Y, Nishikiori R, Shibata S, Shirai K, Fujitani M. Temporary restorative resins using non-phthalate ester plasticizers. J Dent 2005; 33: 577-583.

7) Brännström M, Nordenvall KJ. Bacterial penetration, pulpal reaction and the inner surface of Concise enamel bond. Composite fillings in etched and unetched cavities. J Dent Res 1978; 57: 3-10.

8) Fujimoto Y, Iwasa M, Murayama R, Miyazaki M, Nagafuji A, Nakatsuka T. Detection of ions released from S-PRG fillers and their modulation effect. Dent Mater J 2010; 29: 392-397.

9) Shiiya T, Tomiyama K, Iizuka J, Hasegawa H, Kuramochi E, Fujino F, Ohashi K, Nihei T, Teranaka T, Mukai Y. Effect of the coating material on root dentin remineralization in vitro. Am J Dent 2014; 27: 258-262.

10) Ito S, Iijima $M$, Hashimoto $M$, Tsukamoto $N$, Mizoguchi I, Saito T. Effects of surface pre-reacted glass-ionomer fillers on mineral induction by phosphoprotein. J Dent 2011; 39: 7279 .

11) Ikemura K, Tay FR, Endo T, Pashley DH. A review of chemicalapproach and ultramorphological studies on the development of fluoride-releasing dental adhesives comprising new prereacted glass ionomer (PRG) fillers. Dent Mater J 2008; 27 : 315-339.

12) Kawasaki K, Kambara M. Effects of ion-releasing toothcoating material on demineralization of bovine tooth enamel. Int J Dent 2014; doi: 10.1155/2014/463149.

13) Shiiya T, Mukai $Y$, Tomiyama K, Teranaka T. Antidemineralization effect of a novel fluoride-releasing varnish on dentin. Am J Dent 2012; 25: 347-350.

14) Saku S, Kotake H, Scougall-Vilchis RJ, Ohashi S, Hotta M, Horiuchi S, Hamada K, Asaoka K, Tanaka E, Yamamoto K. Antibacterial activity of composite resin with glass-ionomer filler particles. Dent Mater J 2010; 29: 193-198.

15) Tamura $Y$, Takahashi F, Sumino N, Kawamoto R, Tsujimoto A, Yamaji A, Tsubota K, Kurokawa H, Miyazaki M. A study on marginal sealing of an experimental temporary restorative material containing S-PRG filler. Jpn J Conserv Dent 2013; 56: 193-199.

16) van Strijp AJP, Buijs MJ, ten Cate JM. Contact microradiography of dentine under wet conditions to protect lesion shrinkage. Caries Res 1995; 29: 107-110.

17) Lagerweij MD, de Josselin de Jong E, ten Cate JM. The video camera compared with the densitometer as a scanning device for microradiography. Caries Res 1994; 28: 353-362.

18) Gelhard TB, Arends J. Microradiography of in vivo remineralized lesions in human enamel. II. J Biol Buccale 1984; 12: 59-65.

19) Dijkman AG, Schuthof J, Arends J. In vivo remineralization of 
plaque-induced initial enamel lesions -A microradiographic investigation. Caries Res 1986; 20: 202-208.

20) Heymann HO, Swift EJ, Ritter AV: Sturdevant's Art and Science of Operative Dentistry 6th ed., Elsevier Mosby, St. Louis, Missouri, USA; 2011, p. 489-490.

21) Harsanyi BB, Foong WC, Howell RE, Hidi P, Jones DW. Hamster cheek-pouch testing of dental soft polymers. J Dent Res 1991; 70: 991-996.

22) Ema M, Amano H, Ogawa Y. Characterization of the developmental toxicity of di-n-butyl phthalate in rats. Toxicology 1994; 86: 163-174.

23) Mukai Y, Kamijo K, Fujino F, Hirata Y, Teranaka T, ten Cate JM. Effect of denture base-resin with prereacted glassionomer filler on dentin demineralization. Eur J Oral Sci 2009; 117: 750-754.

24) Kamijo K, Mukai Y, Tominaga T, Iwaya I, Fujino F, Hirata $\mathrm{Y}$, Teranaka T. Fluoride release and recharge characteristics of denture base resins containing surface pre-reacted glassionomer filler. Dent Mater J 2009; 28: 227-233.

25) ten Cate JM, Damen JJM, Buijs MJ. Inhibition of dentin demineralization by fluoride in vitro. Caries Res 1998; 32:
141-147.

26) Larson RH, Mellberg JR, Englander HR, Senning R. Caries inhibition in the rat by water-borne and enamel-bound fluoride. Caries Res 1976; 10: 321-331.

27) Ögaard B, Rölla G, Ruben J, Dijkman T, Arends J. Microradiographic study of demineralization of shark enamel in a human caries model. Scand J Dent Res 1988; 96: 209211.

28) Ngo HC, Mount G, Mc Intyre J, Tuisuva J, Von Doussa RJ Chemical exchange between glass-ionomer restorations and residual carious dentine in permanent molars: an in vivo study. J Dent 2006; 34: 608-613.

29) Thuy TT, Nakagaki H, Kato K, Hung PA, Inukai J, Tsuboi S, Nakagaki H, Hirose MN, Igarashi S, Robinson C. Effect of strontium in combination with fluoride on enamel remineralization in vitro. Arch Oral Biol 2008; 53: 10171022.

30) Besinis A, van Noort R, Martin N. Infiltration of demineralized dentin with silica and hydroxyapatite nanoparticles. Dent Mater 2012; 28: 1012-1023. 